\title{
Generation of Sn Whiskers During Electrodeposition
}

\author{
M. Saitou \\ University of the Ryukyus, Department of Mechanical Systems Engineering, 1 Senbaru Nishihara-cho \\ Okinawa, 903-0213, Japan. \\ "E-mail: saitou@tec.u-ryukyu.ac.jp
}

doi: $10.20964 / 2019.01 .56$

Received: 1 September 2018 / Accepted: 26 October 2018 / Published: 30 November 2018

Sn whiskers generated during electrodeposition on a $\mathrm{Cu}$ plate within a range of the deposition temperature from 273 to $303 \mathrm{~K}$ were investigated using scanning electron microscopy and X-ray diffraction. The critical film thickness for the formation of Sn whiskers on a Sn thin film was determined $(1.9 \mu \mathrm{m})$. The critical film thickness was found to be independent of the deposition temperature. At the film thicknesses more than $5 \mu \mathrm{m}$, the (220) dominant crystallographic plane transformed the (112) plane parallel to the $\mathrm{Cu}$ plate. This can be attributed to the morphological change (coarse to dense $\mathrm{Sn}$ whiskers). This suggests that the Sn whiskers with the (220) plane acted as crystal seeds to generate the Sn whiskers with the (112) plane. The fine string-like Sn whiskers generated at $303 \mathrm{~K}$ during the electrodeposition showed an anomalous growth rate of $45 \mathrm{~nm} \mathrm{~s}^{-1}$ at least.

Keywords: Sn whisker; Electrodeposition; Critical film thickness; Dominant crystallographic plane

\section{FULL TEXT}

(C) 2019 The Authors. Published by ESG (www.electrochemsci.org). This article is an open access article distributed under the terms and conditions of the Creative Commons Attribution license (http://creativecommons.org/licenses/by/4.0/). 